\title{
Successful thrombo-embolectomy in long-standing thrombo-embolic pulmonary hypertension ${ }^{1}$
}

\author{
E. S. NASH, S. SHAPIRO ${ }^{2}$, A. LANDAU, A D C. N. BAR NAR D \\ From the Cardiac Clinic, Departments of Medicine and Surgery, Groote Schuur Hospital, the University of \\ Cape Town, and the Cardiovascular-Pulmonary Research Group, Cape Town
}

The operative removal of thrombo-emboli from the pulmonary arteries in acute pulmonary embolism is an accepted method of treatment. The removal of thrombi that have been present for many months has been attempted less often. This case report covers the operative treatment and the pre- and post-operative physiological studies in a patient with long-standing thromboembolic pulmonary hypertension, in whom a large thrombus was removed under cardiopulmonary bypass from the left pulmonary artery. Dramatic clinical improvement resulted. A plea is made for a more radical approach to thrombo-embolic pulmonary hypertension when a local obstruction can be demonstrated.

Current clinical and experimental evidence suggests that pulmonary embolism is primarily a mechanical problem (Knisely, Wallace, Mahaley, and Satterwhite, 1957 ; Gorham, 1961 ; Sabiston and Wagner, 1965; Moser, Houk, Jones, and Hufnagel, 1965). This makes the operative removal of emboli from the pulmonary vessels a logical form of treatment. After Trendelenburg's (1908) experimental and surgical attempts, several surgeons followed suit, but the formidably high mortality rate with only 23 documented survivors (Milligan, Olsen, Toole, and Wood, 1966) discouraged the widespread adoption of operative removal and it fell into disrepute. After 1944, with the advent of anticoagulant therapy, this became the treatment of choice (Barritt and Jordan, 1960), the aim being to prevent the formation of further thrombi, and, as a result, operation for removal of thrombi became even less popular. However, with the growing safety of thoracic surgery and the introduction of cardiopulmonary bypass, interest in a surgical approach to the problem has been once more revived. Most case reports, following Steenburg's challenge in 1958 (Steenburg, Warren, Wilson, and Rudolf, 1958), focus on the place of pulmonary embolectomy as a life-saving measure in acute pul-

${ }^{1}$ Read at the 46th South African Medical Congress, Durban, July 1967

Supported in the Department of Medicine by the South African Council for Scientific and Industrial Research

2Present address: Department of Medicine, Lemuel Shattuck Hospital, 170 Morton Street, Boston, Mass., U.S.A. monary embolism (Allison, Dunnill, and Marshall, 1960 ; Hampson, Milne, and Small, 1961 ; Sharp, 1962 ; Cooley and Beall, 1962 ; Sautter, Lawton, Magnin, and Emanuel, 1963).

The operative removal of thrombo-emboli from the pulmonary vessels of patients with recurrent thrombo-embolism with pulmonary hypertension has been attempted less often.

The successful removal of major thrombi many months after the initial embolic episode has been reported (Houk, McClenathan, Hufnagel, and Moser, 1963 ; Snyder, Kent, and Baisch, 1963 ; Moser et al., 1965; Makey and Bliss, 1966). We here report a case of severe thrombo-embolic pulmonary hypertension in whom operative relief was successfully carried out at least a year after the last clinical episode of pulmonary embolism, and six months after angiographic demonstration of the obstruction.

\section{CASE REPORT}

In November 1963 O. M., a white man aged 63, had phlebitis of the left leg. He was seen by a doctor, who advised rest and an elastic support. This was used for a while and then discarded. He remained well until May 1965, when he developed phlebitis of the right leg, which subsided after one week. On 23 June 1965 he was lifting a heavy weight when, without warning, he felt as if something had suddenly burst inside his chest. He became severely breathless and was aware of vague substernal discomfort. 
The breathlessness persisted, and a day or two later he developed a cough with blood-stained sputum and fever $\left(104^{\circ} \mathrm{F}\right.$., $39 \cdot 8^{\circ} \mathrm{C}$.), which subsided after a week in bed. He remained breathless on effort and by 14 August he could manage only a short distance without distress. He consulted a doctor, and a radiograph of the chest was taken. As the right hilum was con- sidered to be prominent a bronchoscopy was per- $\overrightarrow{\overrightarrow{\vec{N}}}$ formed to exclude cancer. Nothing abnormal was $\bar{C}$ found.

On 31 August 1965 he developed severe pleuritic pain at the left lung base, for which he was put to bed for two weeks. On this occasion there was some cough but no sputum nor haemoptysis. On getting $\mathscr{\omega}$

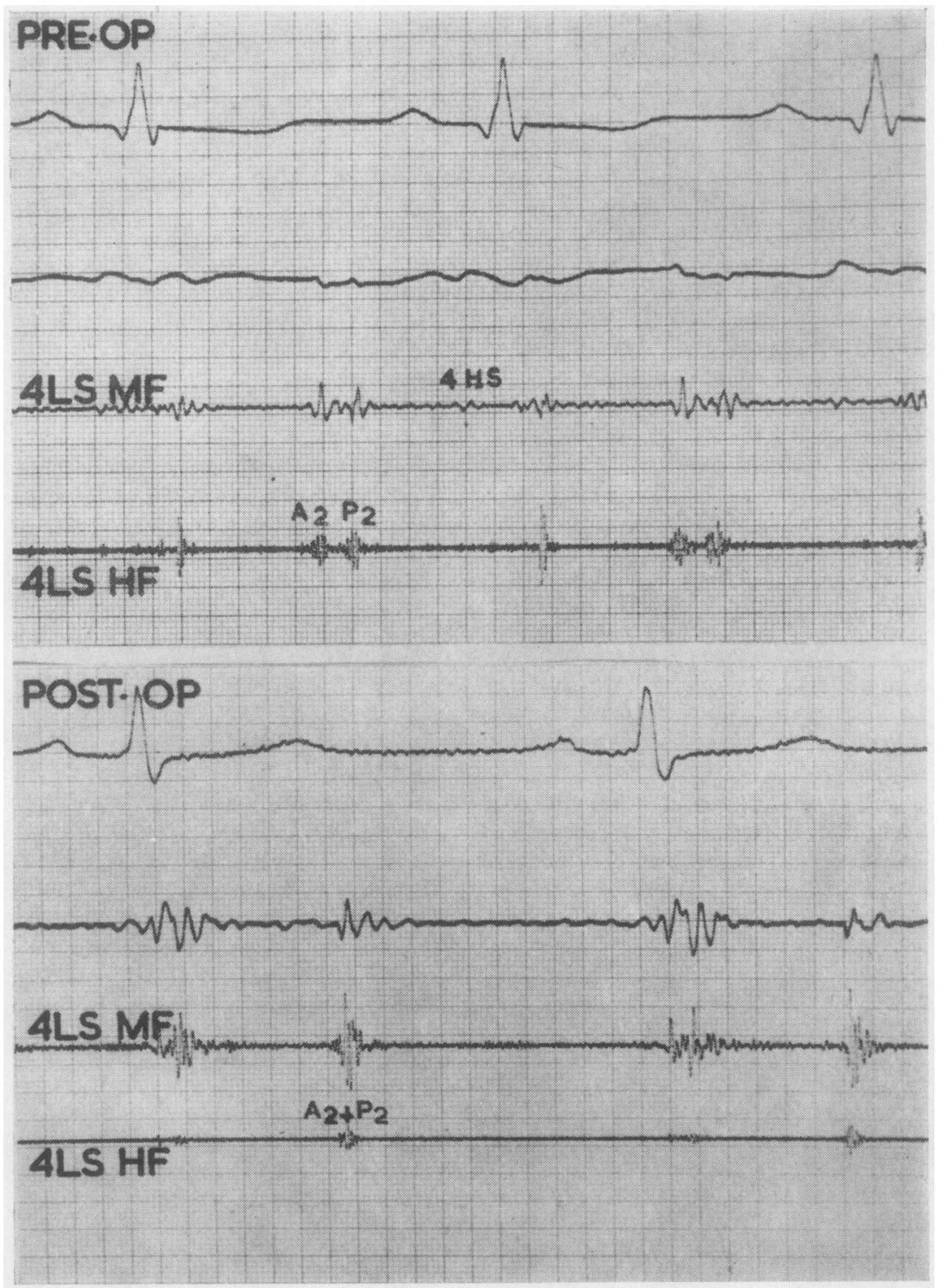

FIG. 1. Pre-operative and post-operative phonocardiograms taken at the fourth left interspace. Pre-operatively the aortic and pulmonary components of the second sound are split by $0.07 \mathrm{sec}$. and they become virtually fused following operation. $A$ fourth heart sound is present pre-operatively. (Recordings in full expiration. Time marking $0.01 \mathrm{sec}$.) 
about again, he noted severe breathlessness on minimal exertion, and swelling of both legs. He was found to be in congestive cardiac failure and was treated with digoxin and frusemide with improvement of the oedema but no relief of dyspnoea. Because of his history, clinical course, and a radiograph of the chest, which suggested the diagnosis of pulmonary thrombo-embolic disease, he was referred for assessment on 30 November 1965.
Examination $\mathrm{He}$ was a well-set man (weight $180 \mathrm{lb}$.; $81.6 \mathrm{~kg}$.) with evidence of recent loss of weight. There was no cyanosis nor clubbing. His blood pressure was $170 / 110 \mathrm{~mm} . \mathrm{Hg}$ and pulse rate 96 per minute. The jugular venous pressure was elevated to $6 \mathrm{~cm}$. with a dominant ' $a$ ' wave and rapid ' $x$ ' descent. In the precordium there was marked right ventricular lift and a palpable fourth heart sound. In the pulmonary area there was a soft first sound, a loud ejection click,

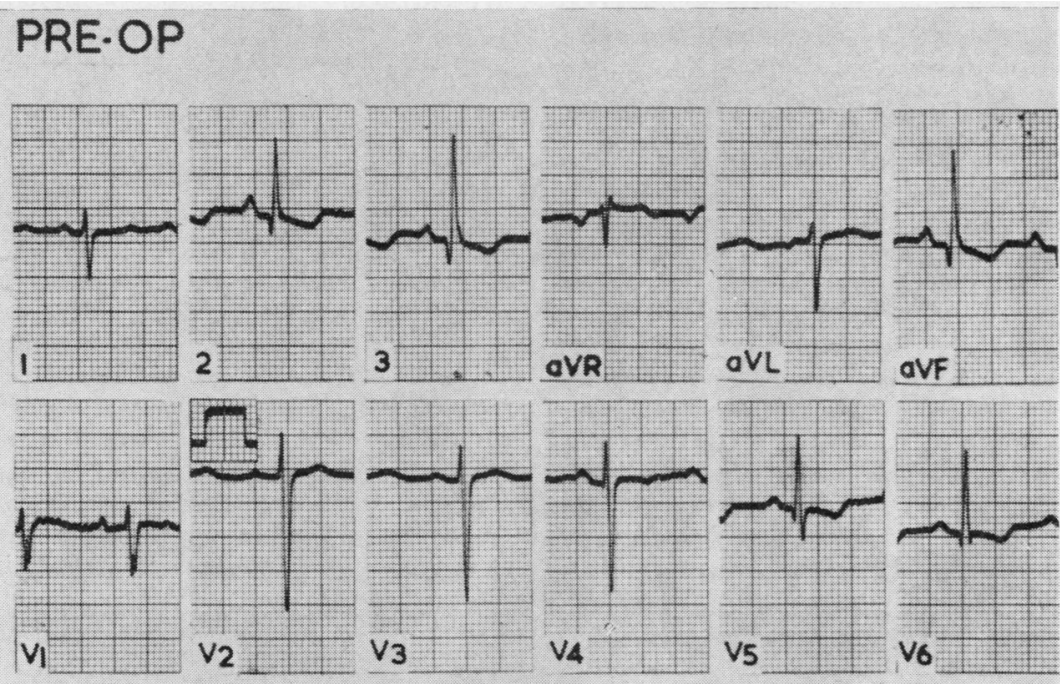

\section{POST-OP}
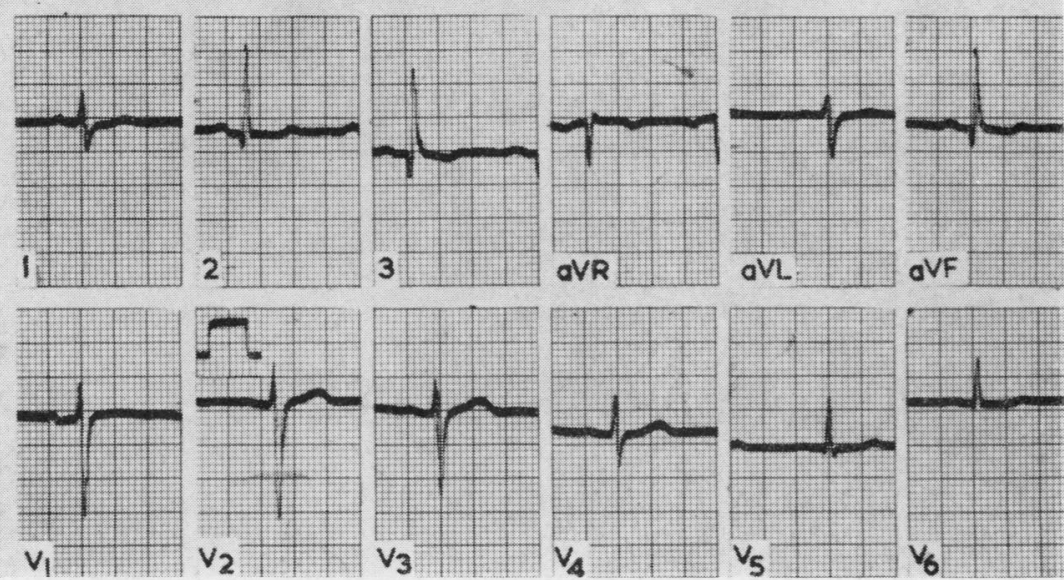

FIG. 2. Pre-operative E.C.G. shows a mean frontal axis of +100 , markedly peaked $P$ waves, incomplete right bundle-branch block, and persistence of $S$ waves through to $V_{6}$. Extensive $T$-wave inversion is also present (on digitalis). Postoperative E.C.G. shows a mean frontal axis of +90 , the $P$ waves have reverted to normal, and the incomplete right bundle-branch block has disappeared. The $S$ waves are present up to $V_{5}$ and even here they are far less prominent. Nonspecific ST changes are still present due to digitalis. 
and a wide split between the aortic and pulmonary components of the second sound. The latter component was accentuated. Along the left sternal edge there was a loud fourth heart sound. At the mitral area the sounds were normal. There were no murmurs (Fig. 1). The liver was palpable $2 \mathrm{~cm}$. below the costal margin. A prominent feature was apparent excessive ventilation at rest (with normal respiratory rate) aggravated by the least exertion. Chest shape and expansion were normal. The breath sounds were normal and there were no added sounds. The calves of both legs were thickened, and superficial varicosities with pitting oedema were present in both legs.

Investigations The haemoglobin was $14.5 \mathrm{~g} . / 100 \mathrm{ml}$. W.B.C. 9,650 cells $/ \mathrm{cm}^{3}$ Urinalysis was normal. The electrocardiogram (Fig. 2) showed a mean frontal axis of +100 . There were markedly peaked $P$ waves and persistence of the $S$ waves over the left ventricular leads through to $V_{6}$. The $T$ waves were inverted in the same leads. The QRS complexes showed the pattern of incomplete right bundle-branch block. Radiography of the chest (Fig. 3) showed hyperlucency of the left lung field due to a marked reduction in the normal bronchovascular markings. This included the left hilar shadows. The right side appeared to be normal. The heart was moderately enlarged.
Cardiac catheterization and angiography were carried out on 30 December 1965 (Table I). The patient was studied at rest and during steady-state exercise with a load of $250 \mathrm{kpm}$. per minute. The data showed that he had an elevated mean right atrial pressure, indicating congestive cardiac failure, with a dominant ' $a$ ' wave of $17.5 \mathrm{~mm}$. The right ventricular end-diastolic pressure was grossly raised. There was pulmonary hypertension as well as mild systemic hypertension. It was not possible to wedge the catheter; nevertheless, assuming a mean wedge pressure of $15 \mathrm{~mm}$. (the upper limit of normal for our laboratory), this gave a calculated pulmonary vascular resistance of 8 units. The cardiac index was abnormally low, as was the stroke index. Following exercise there was a striking increase in the main pulmonary artery pressure and a rise in the right brachial pressure. The cardiac index increased, this being due solely to the increase in the heart rate, since the stroke index remained constant. There was a sharp drop in the mixed venous oxygen saturation, suggesting increased oxygen extraction by the tissues. The blood chemistry at rest revealed a compensated respiratory alkalosis with a low $\mathrm{PCO}_{2}$, and the $\mathrm{Po}_{2}$ was markedly reduced $(62 \mathrm{~mm}$.). Following exercise the $\mathrm{Po}_{2}$ rose to $85 \mathrm{~mm}$. There was a corresponding slight improvement in the oxygen saturation. (The $\mathrm{PCO}_{2}$ dropped even further.) A pulmonary arteriogram

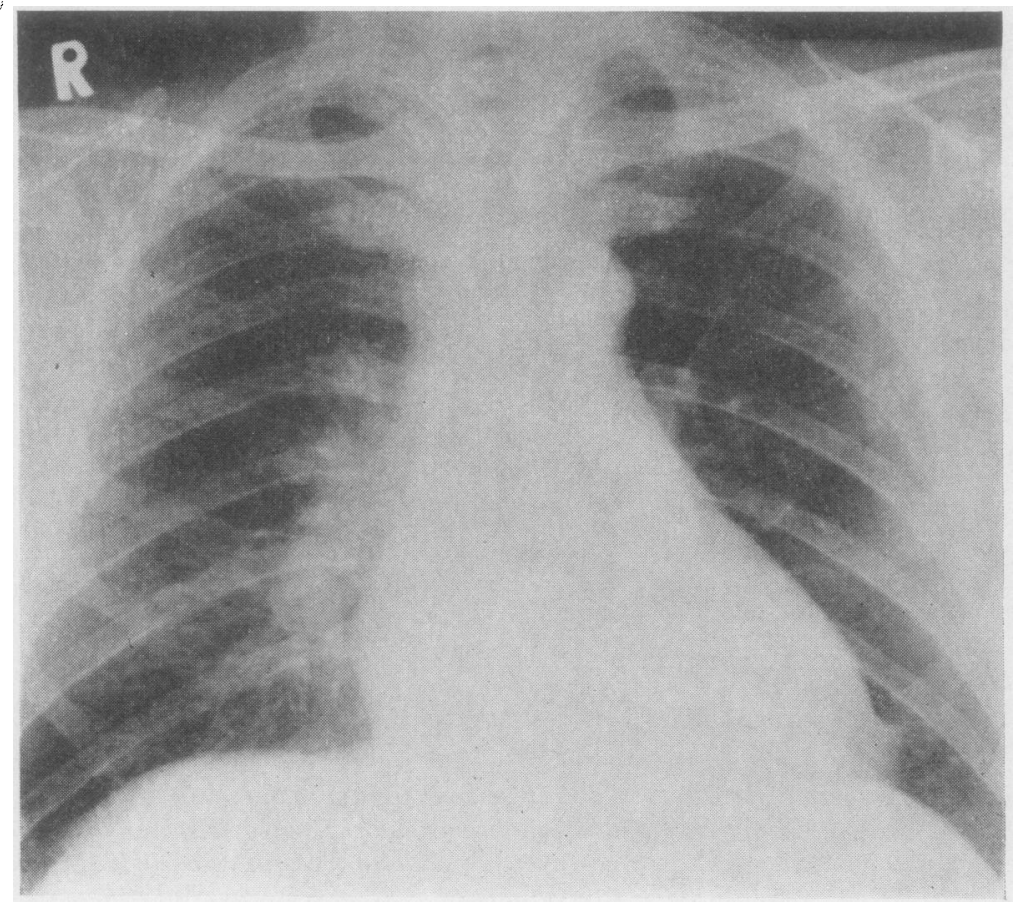

FIG. 3. Radiograph of chest 1.6 .66 (pre-operatively) shows some cardiac enlargement and prominence of the right pulmonary artery. On the left side a few thready vessels can be seen with hyperlucency of the lung field. 


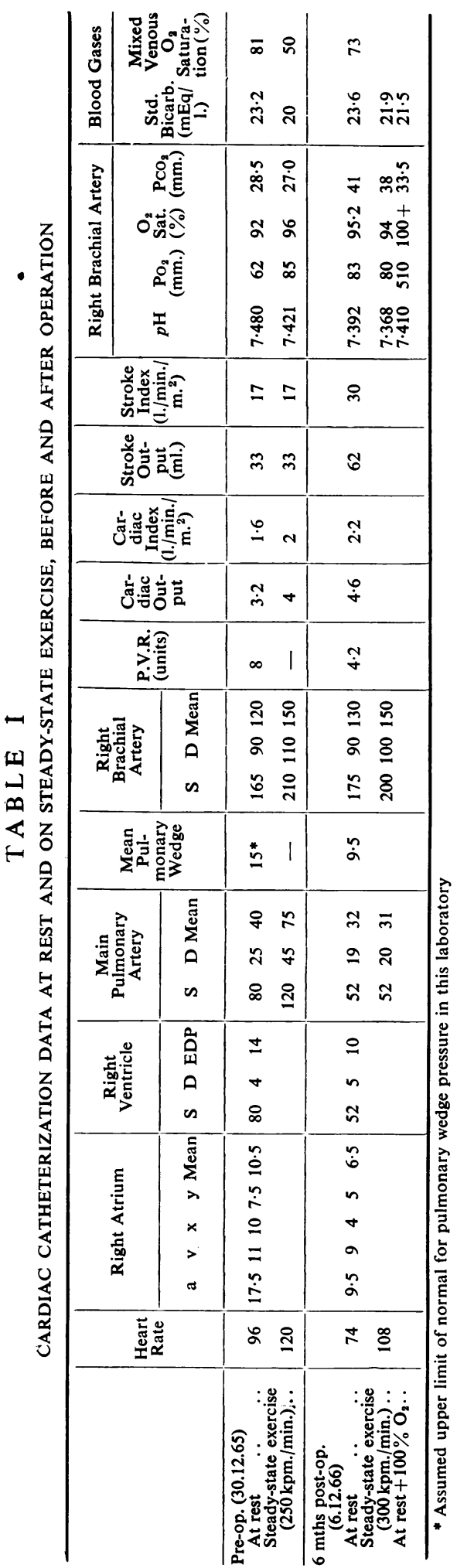

showed almost complete occlusion of the left main pulmonary artery, with only a few thread-like blood vessels radiating from the left hilum into the lung (Fig. 4). The right pulmonary artery was also abnormal, and the right mid-zone was avascular. There also appeared to be a narrowing just distal to the origin of the right upper lobe artery and this vessel filled poorly. The only areas of lung which appeared to have a good blood supply were the right middle and lower lobes.

Surgical relief of the obstruction to the left main pulmonary artery was considered and declined, but over the next few months the patient became totally incapacitated despite anticoagulant therapy. Even dressing produced intense dyspnoea, and he was barely able to walk across a room. Eventually it was decided that, despite the hazards of surgery, of which the patient was well aware, an attempt should be made to relieve the obstruction. Accordingly, on 6 June 1966 pulmonary embolectomy was performed.

The heart and left pulmonary artery were exposed through a left thoracotomy at the level of the fourth rib. On opening the pericardium it was found that the right side of the heart was dilated and hypertrophied. On palpation the pulmonary artery was tense and a firm thrombus could be felt in the periphery of the left pulmonary artery.

Cardiopulmonary bypass was established by drainage of the venous blood, using a cannula in the right atrium and returning the oxygenated blood to the left common femoral artery. The main pulmonary artery was opened and the incision was extended up to the bifurcation of this vessel. A thrombus was found occluding the main pulmonary artery up to this point, and thrombi could also be seen in the periphery of the left pulmonary artery.

A line of cleavage was established between the thrombus and the left pulmonary artery wall, and this was then very carefully dissected, using blunt dissection, right down into the smaller branches as far as possible. The whole thrombus was removed (Fig. 5), and immediately a good back-flow of blood was observed from the left pulmonary artery. An attempt was made to remove as much of the thrombus occluding the branches of the right pulmonary artery as possible, but, on account of the approach used, it was not possible to clear this vessel.

The pulmonary arteriotomy was closed and bypass was discontinued. It was immediately noticed that the pressure in the main pulmonary artery was lower than before the operation. The pericardium and left pleural cavity were drained and the wound was closed in the conventional manner.

The abdomen was then prepared. The inferior vena cava was exposed extraperitoneally through a right flank incision, and this vessel was ligated below the renal veins.

The post-operative period was stormy. Haemorrhage from the chest wall vessels necessitated a repeat thoracotomy. Thereafter he developed haematuria with intermittent obstruction by clots and urethritis 


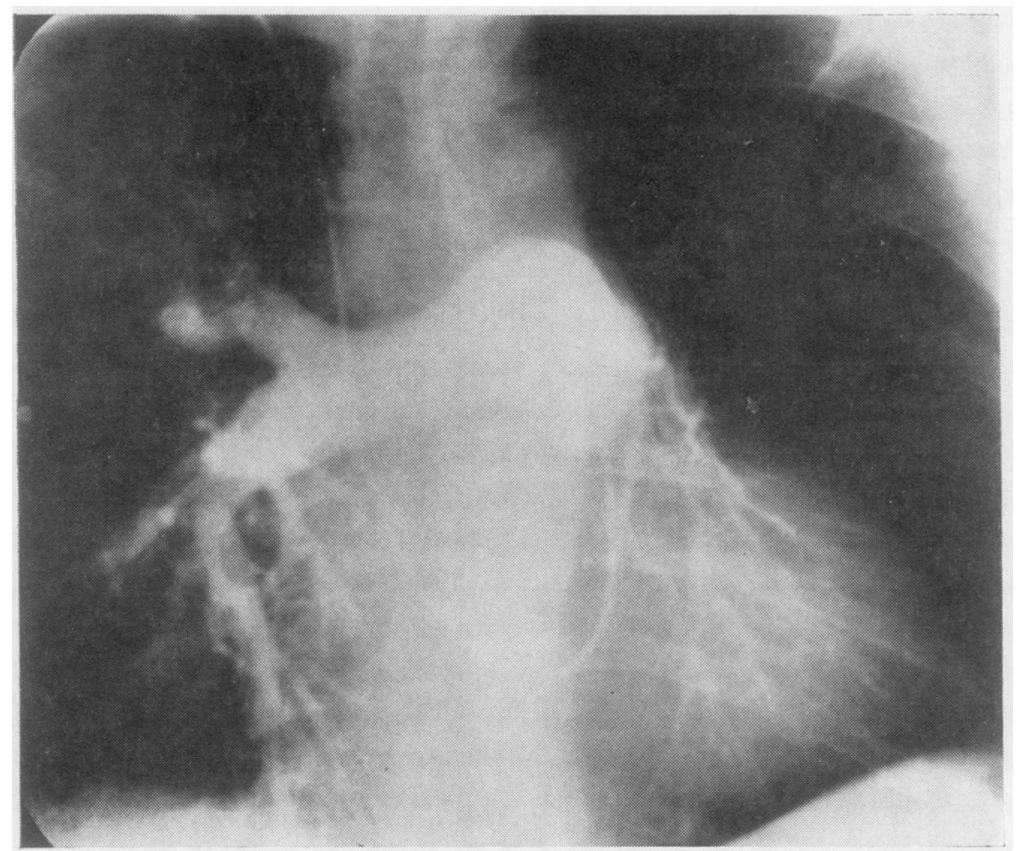

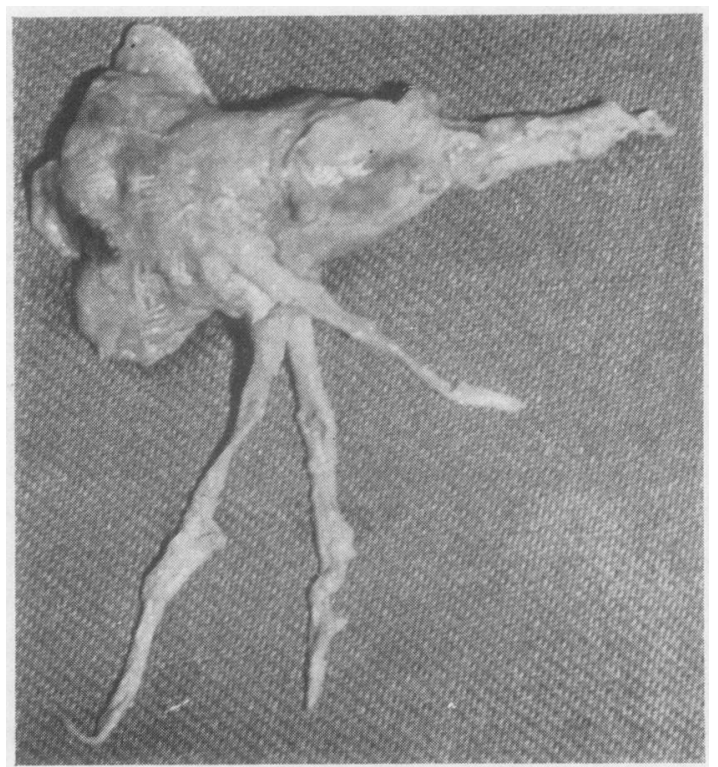

FIG. 5. Photograph of the clot forming a cast of the left main pulmonary artery and its radicals. following catheterization. Ultimately, a prostatectomy had to be done, and at operation the surgeon noted grossly dilated submucosal veins in the bladder; these were ligated. He then developed severe orchitis which responded to kanamycin therapy. Eventually after two months he was discharged from hospital feeling relatively well.

Arterial blood gases, 12 weeks after operation, were still abnormal (Table II). However, the patient noted great subjective improvement. He was able to walk almost 50 yards $(45 \mathrm{~m}$.) without undue dyspnoea He had again been put on to permanent anticoagulant treatment and was seen at monthly intervals. He continued to report steady improvement.

At the time of writing he is engaged in a fuln day's work and experiences no distress. He can climb three or four flights of steps without stopping anck feels better than at any time since the start of hif illness. On examination he looks well. All evidence of right-sided heart failure has disappeared; the pul? monary second sound is not accentuated and splitso normally; the fourth heart sound can no longer be heard (Fig. 1). His legs remain oedematous, probably due to the obstructed venous return. The chest radiograph now shows normal pulmonary vasculature in the left lung (Fig. 6). The electrocardiogram hax shown a shift of the axis to $+90^{\circ}$ and the incompleter 
T A B L E II

PULMONARY FUNCTION DATA

\begin{tabular}{|c|c|c|c|c|c|c|c|c|c|c|c|c|c|}
\hline & $\begin{array}{l}\text { Vital } \\
\text { Capacity } \\
\text { (1.) }\end{array}$ & $\begin{array}{l}\text { F.E.V.1 } \\
(1 . / \mathrm{sec} .)\end{array}$ & $\begin{array}{l}\text { Max. } \\
\text { Vol. } \\
\text { Vent. } \\
\text { (1./min.) }\end{array}$ & $\begin{array}{c}\text { Min. } \\
\text { Vent. } \\
\text { (l./min. })\end{array}$ & f & $\begin{array}{l}\text { Tidal } \\
\text { Vol. } \\
\text { (1.) }\end{array}$ & $p \mathrm{H}$ & $\underset{(\mathrm{mm} .)}{\mathbf{P o}_{2}}$ & $\begin{array}{l}\mathrm{O}_{2} \\
\text { Sat. }\end{array}$ & $\begin{array}{c}\text { PCO, }_{2} \\
\text { (mm.) }\end{array}$ & $\begin{array}{l}\text { Base } \\
\text { Exc. }\end{array}$ & $\begin{array}{l}\text { Std. } \\
\text { Bicarb. } \\
\text { (mEq./ }\end{array}$ & $\begin{array}{c}(\mathrm{a}-\mathrm{A}) \\
\mathbf{C O}_{\mathbf{2}} \\
\text { Gradient }\end{array}$ \\
\hline \multirow{5}{*}{$\begin{array}{l}\text { Predicted } \\
\text { Pre-op. } \\
\text { (30.11.65) } \\
\text { Post-op. } \\
\text { (12 weeks) } \\
\text { (26.8.66) }\end{array}$} & $4 \cdot 15$ & $>81 \%$ & 92 & \multirow[b]{2}{*}{$24 \cdot 8$} & \multirow[b]{2}{*}{14} & \multirow[b]{2}{*}{$1 \cdot 77$} & \multirow{3}{*}{$\begin{array}{l}7 \cdot 40 \\
\text { At rest } \\
7 \cdot 461 \\
\text { At rest } \\
7 \cdot 410\end{array}$} & $89 *$ & 97 & 40 & 0 & 25 & 0 \\
\hline & $5 \cdot 05$ & $\begin{array}{c}3.09 \\
(61 \%)\end{array}$ & 137 & & & & & 67 & 93 & 32 & 0 & 24 & - \\
\hline & \multirow[t]{3}{*}{4.08} & \multirow[t]{3}{*}{$(75 \%)$} & \multirow[t]{3}{*}{160} & \multirow[t]{3}{*}{$11 \cdot 0$} & \multirow[t]{3}{*}{14} & \multirow[t]{3}{*}{0.785} & & 68 & 93 & 33 & $-3 \cdot 1$ & $21 \cdot 3$ & 0 \\
\hline & & & & & & & \multirow{2}{*}{\multicolumn{3}{|c|}{ 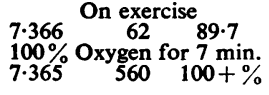 }} & 39 & $-3 \cdot 0$ & $21 \cdot 6$ & \\
\hline & & & & & & & & & & 34 & $-4 \cdot 7$ & 20.5 & $i$ \\
\hline
\end{tabular}

$* \mathrm{PaO}_{2}$ in $\mathrm{mm} .=102.5-(0.22 \times$ age $)($ Conway $)$

right bundle-branch block has disappeared; the $\mathrm{S}$ waves have become less prominent over the left ventricular leads, and the $T$ waves have become upright (Fig. 2). Repeat cardiac catheterization studies were carried out on 6 December 1966 (Table I), and these showed a normal right atrial pressure, a normal ' $a$ ' wave, moderately raised pulmonary artery pressure, slightly raised right ventricular end-diastolic pressure, moderate systemic hypertension, normal cardiac output, and normal stroke index. The pulmonary vascular resistance had fallen from 8 to 4 units. The pulmonary artery pressure remained virtually unchanged after exercise, and there was a slight increase in the systemic arterial pressure. Blood gases were almost normal.

The pulmonary arteriogram showed a full patent left main pulmonary artery with perfusion of the entire lung (Fig. 7). The angiocardiographic features in the right lung were essentially unchanged. By comparison it became obvious that even the right lower lobe, thought pre-operatively to be adequately perfused, was in fact also underperfused. Most of the pulmonary blood flow appeared to be going to the left lung.

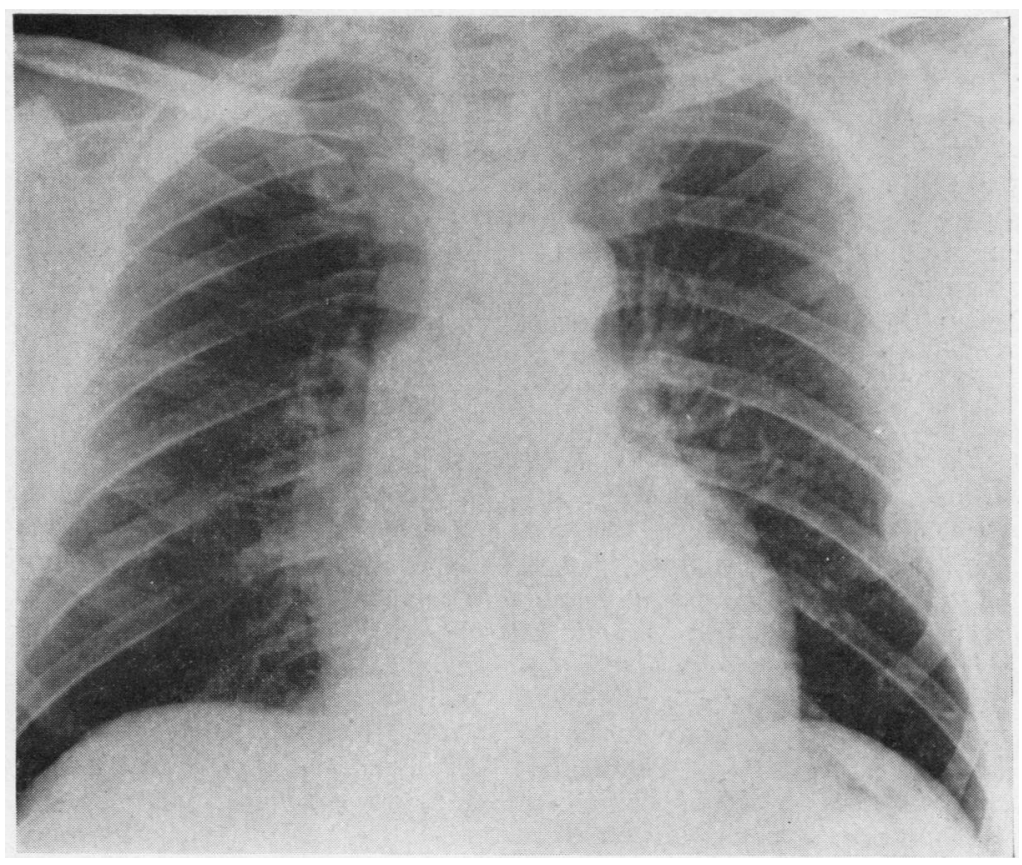

FIG. 6. Post-operatively (14.12.66) the heart is still enlarged though smaller in size, and the left lung is now well vascularized. 


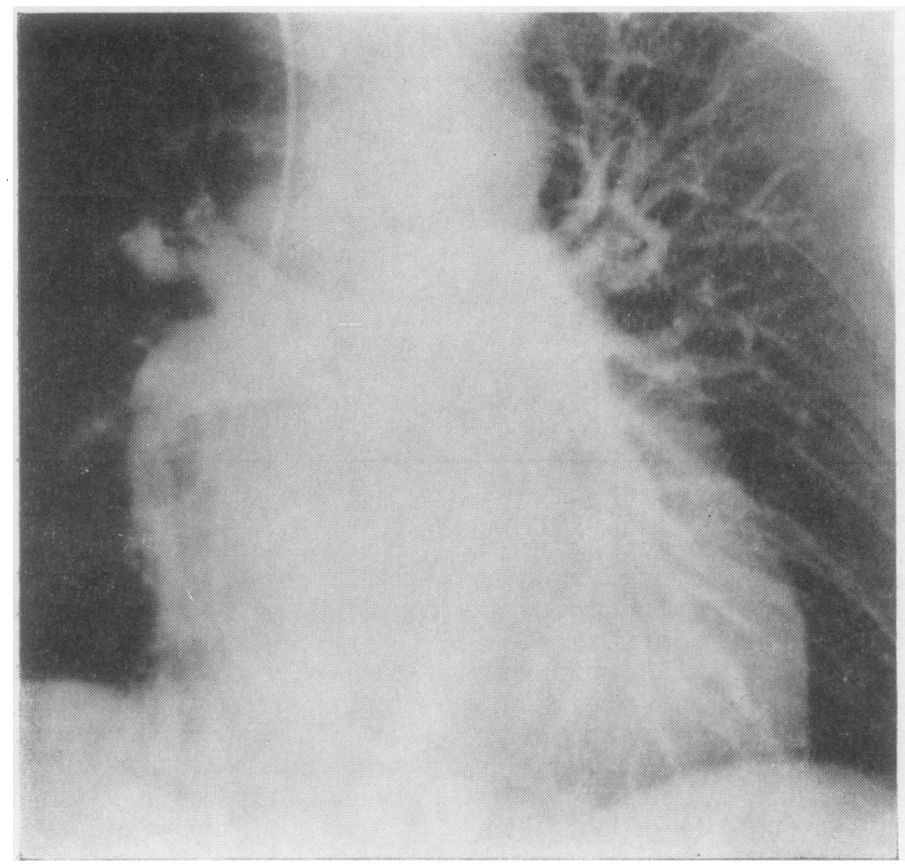

FIG. 7. Post-operatively (6.12.66) there are large patent vessels in all areas of the left lung. The appearances of the vessels in the right lung are unchanged.

\section{DISCUSSION}

Thrombo-embolic pulmonary hypertension is not rare, and, once remembered, there should be few diagnostic difficulties (Ball, Goodwin, and Harrison, 1956 ; Houk et al., 1963 ; Goodwin, Harrison, and Wilcken, 1963 ; Gray, 1966). In some patients there is a history of peripheral thrombo-phlebitis together with bouts of chest pain, dyspnoea, and sometimes haemoptysis, often attributed to a respiratory infection. In the course of time some patients develop dyspnoea which eventually may become crippling. Fatigue and exertional syncope are common accompanying features. If the patient is examined at this stage there is usually rightsided failure with a dominant ' $a$ ' wave, an enlarged right ventricle, delayed closure of the pulmonary valve on auscultation (Shapiro, Clark, and Goodwin, 1965), and an accentuated pulmonary component of the second sound. A striking feature is usually the severe degree of the respiratory distress which may be present with few physical signs in the lungs to account for it ; the breath sounds may be well heard throughout the chest. The chest radiograph shows pruning of the peripheral pulmonary arteries, an enlarged main pulmonary artery, and right ventricular and right atrial enlargement. The electrocardiogram characteristically shows right axis deviation and evidence of right ventricular and right atrial hypertrophy. Usually there is persistence of the $S$ waves over the left ventricular leads, and there may be extensive $\mathrm{T}$-wave inversion as well.

Sometimes the clinical presentation is more subtle ; there may be no clear-cut story of swelling or of pain in the limbs, or any history of a respiratory disorder at all. The presenting features in such patients may simply be dyspnoea and rightsided failure without obvious parenchymal lung disease. The pulmonary second sound may be soft and there may be no obvious right ventricular hypertrophy clinically. Occasionally the patient may present with such symptoms as angina pectoris and severe fatigue, and the only striking features are cold extremities due to vasoconstriction in response to low cardiac output. In the early stages some patients may be labelled neurotic. Probably the most important criterion in successfully diagnosing such patients is awareness of the condition, and even the difficult cases should not present insuperable diagnostic problems. Confirmation is by means of cardiac catheterization and pulmonary arteriography. Pulmonary function studies characteristically reveal alveolar hyperventilation, hypoxia, and an increased a-A $\mathrm{CO}_{3}$ gradient (Heilman, Tabakin, Hanson, and Naeye, 1962 ; Jones and Goodwin, 1965). 
The prognosis in most patients with thromboembolic hypertension is poor, and they tend to follow an inexorable course with progressive rightsided failure, crippling dyspnoea, and ultimate death (Phear, 1960 ; Goodwin et al., 1963 ; Houk et al., 1963). Some patients have, however, recovered on anticoagulant therapy (Dexter, 1957 ; Wood, 1958 ; Wilcken, MacKenzie, and Goodwin, 1960). If further embolism can be prevented in this way, lysis of old clot may result in restoration of the lumen (Hume, Glenn, and Grillo, 1960).

Since the problem has appeared to be basically mechanical, surgical removal of the clots has been suggested; but the objection has been raised that the clots may have become fibrosed and organized and may have propagated down the smaller branches of the pulmonary artery to surgically inaccessible areas. This reasoning has been responsible for inhibiting the surgical approach to the disease. It now seems probable that a vessel may be obstructed by a large thrombus for months or even years without extensive invasion by fibrous tissue. Even if organization does occur along the periphery of the thrombus, it may still be removable. Our patient once again illustrates that it is possible not only to remove the clot from the main pulmonary artery but also to extract some of the extensions down the secondary branches as well. This was accomplished in spite of the fact that obstruction is known to have been present for at least six months and had almost certainly been in situ for a year.

In recent years there have been a few attempts at operative relief of thrombo-embolic hypertension (Hurwitt, Schein, Rifkin, and Lebendiger, 1958; Snyder et al., 1963 ; Case Records of the Massachusetts General Hospital, 1964 ; Winterscheid, Dillard, Blackmon, Figley, Crawford, and Merendino, 1965 ; Frater, Beck, and Schrire, 1965 ; Moser et al., 1965 ; Makey and Bliss, 1966). Some have failed, but there have been a few striking successes. Moser et al. (1965) reported a series of four cases on whom they operated, two of them successfully. They carried out detailed haemodynamic and respiratory studies before and after operation in a successful case, and they were able to show striking functional improvement following operation. A similar gratifying improvement was obtained in our patient. Some angiographic and haemodynamic abnormalities remain, but they are not nearly as severe as they were and may yet improve further.

The advent of bypass techniqués has encouraged the surgical approach to this disease by increasing its safety, although, depending on the location of the thrombus, it is sometimes possible to cross- clamp the artery and remove the clot without resorting to bypass (Steenburg et al., 1958). Cardiopulmonary bypass should at least be available so that if there are any technical difficulties it can be used (Sharp, 1962; Cooley and Beall, 1962). Operation was carried out on our patient as an act of desperation, and, having met with success, we would now be tempted to operate whenever the clot appears to be obstructing an artery large enough for a surgical approach to be feasible. In view of the poor prognosis with conservative management and anticoagulation, it seems to us that this is justifiable. Unexpected post-operative complications may occur-for example, operative removal of thrombo-emboli of eight weeks' standing was unsuccessful in one patient in whom haemorrhage occurred into the revascularized lobes, with death from hypoxia (Case Records of the Massachusetts General Hospital, 1964).

We believe that a firm place has been established for the operative treatment of selected cases of recurrent thrombo-embolic pulmonary hypertension. The total number of case reports to date is small, and not all patients survived the operation. The surgeon may still encounter unforeseen technical difficulties. With this in mind, we suggest the following criteria for selection:

1. Patients who are sufficiently disabled;

2. Patients who have no underlying chronic lung or heart disease ;

3. The patient should have severe thromboembolic pulmonary hypertension demonstrable at cardiac catheterization. The vascular obstruction should be determined by pulmonary arteriography. Such patients will invariably have gross disturbance of respiratory function as well ;

4. The obstruction must be present in one or both major branches of the pulmonary artery. If the pulmonary angiogram shows multiple small obstructions in the distal vessels, without major artery obstruction, then surgery can be of no assistance.

We wish to thank Professor V. Schrire, Director of the Cardiac Clinic, Groote Schuur Hospital, for his guidance and direction of the management of this patient, and Dr. J. G. Burger, Superintendent of Groote Schuur Hospital, for permission to publish. also the South African Council for Scientific and Industrial Research and the City Council of Cape Town for their financial support.

\section{REFERENCES}

Allison, P. R., Dunnill, M. S., and Marshall, R. (1960). Pulmonary embolism. Thorax, 15, 273.

Ball, K. P., Goodwin, J. F., and Harrison, C. V. (1956). Massive thrombotic occlusion of the large pulmonary arteries. Circulation 14. 766 . 
Barritt, D. W., and Jordan, S. C. (1960). Anticoagulant drugs in the treatment of pulmonary embolism. A controlled trial. Lancet, 1 , 1309.

Case Records of the Massachusetts General Hospital (Case 32-1964). (1964). New Engl. J. Med., 271, 40.

Cooley, D. A., and Beall, A. C. (1962). Surgical treatment of acute massive pulmonary embolism using temporary cardiopulmonary bypass. Dis. Chest, $41,102$.

Dexter, L. (1957). Case records of the Massachusetts Gen eral Hospital (Case 43311-1957). New Engl. J. Med., 257, 235.

Frater, R. W. M., Beck, W., and Schrire, V. (1965). The syndrome of pulmonary artery aneurysms, pulmonary artery thrombi, and peripheral venous thrombi. J. thorac. cardiovasc. Surg., 49, 330.

Goodwin, J. F., Harrison, C. V., and Wilcken, D. E. L. (1963). Obliterative pulmonary hypertension and thrombo-embolism. Brit. med. J., 1, 701, 777 .

Gorham, L. W. (1961). A study of pulmonary embolism. Arch. intern. Med., 108, 8, 189, 418.

Gray, F. D., Jr. (1966). Pulmonary Embolism. Lea and Febiger, Philadelphia.

Hampson, J., Milne, A. C., and Small, W. P. (1961). The surgical treatment of pulmonary embolism. Lancet, 2, 402.

Heilman, R. S., Tabakin, B. S., Hanson, J. S., and Naeye, R. L. (1962) Alterations of circulatory and ventilatory dynamics in pulmonary vascular obstruction secondary to recurrent pulmonary emboli. Amer. J. Med., 32, 298.

Houk, V. N., McClenathan. J. E., Hufnagel, C., and Moser, K. M. (1963). Chronic thrombotic obstruction of major pulmonary arteries. Ibid., 35, 269.

Hume, M., Glenn, W. W. L., and Grillo, T. (1960). Behavior in the circulation of the radioactive pulmonary embolus and its application to the study of fibrinolytic enzymes. Ann. Surg., 151, 507.

Hurwitt, E. S., Schein, C. J., Rifkin, H., and Lebendiger, A. (1958). A surgical approach to the problem of chronic pulmonary artery obstruction due to thrombosis or stenosis. Ibid., 147, 157.

Jones, N. L., and Goodwin, J. F. (1965). Respiratory function in pulmonary thromboembolic disorders. Brit. med. J., 1, 1089
Knisely, W. H., Wallace, J. M., Mahaley, M. S., Jr., and Satterwhite, $\stackrel{\overline{\bar{\omega}}}{\overparen{H}}$ W. M., Jr. (1957). Evidence, including in vivo observations, suggesting mechanical blockage rather than reflex vasospasm as the cause of death in pulmonary embolization. Amer. Heart $J$. $54,483$.

Makey, A. R., and Bliss, B. P. (1966). Pulmonary embolectomy. Lancet, 2,1155 .

Milligan, R. S., Olsen, P. A., Toole, G. J., and Wood, N. E. (1966). Surgical treatment of massive pulmonary embolism. Calif. Med., $104,204$.

Moser, K. M., Houk, V. N., Jones, R. C., and Hufnagel, C. C. (1965). Chronic, massive thrombotic obstruction of the pulmonary arteries. Circulation, 32, 377.

Phear, D. (1960). Pulmonary embolism. A study of late prognosis. Lancet, $2,832$.

Sabiston, D. C., and Wagner, H. N. (1965). The pathophysiology of pulmonary embolism: relationships to accurate diagnosis and choice of therapy. J. thorac. cardiovasc. Surg., 50, 339.

Sautter, R. D., Lawton, B. R., Magnin, G. E., and Emanuel, D. A $\omega$ (1963). Pulmonary embolectomy. New Engl. J. Med., 269, 997. N

Shapiro, S., Clark, T. J. H., and Goodwin, J. F. (1965). Delayed $\vec{N}$ closure of the pulmonary valve in obliterative pulmonary hypertension. Lancet, 2, 1207.

Sharp, E. H. (1962). Pulmonary embolectomy. Ann. Surg., 156, 1.

Snyder, W. A., Kent, D. C., and Baisch, B. F. (1963). Successful endarterectomy of chronically occluded pulmonary artery. $J$ thorac. cardiovasc. Surg., 45, 482.

Steenburg, R. W. Warren, R. Wilson, R. E., and Rudolf, L. E (1958). A new look at pulmonary embolectomy. Surg. Gynec. Obstet., 107, 214.

Trendelenburg, F. (1908). Operative interference in embolism of the pulmonary artery. Translation in Ann. Surg., 48, 772.

Wilcken, D. E. L., MacKenzie, K. M., and Goodwin, J. F. (1960). Anticoagulant treatment of obliterative pulmonary hypertension. Lancet, 2, 781.

Winterscheid, L. C., Dillard, D. H., Blackmon, J. R., Figley, M. N. Crawford, E. W., and Merendino, K. A. (1965). The spectrum of patients with pulmonary embolism. Amer. J. Surg., 110, 247.

Wood, P. (1958). Pulmonary hypertension with special reference to the vasoconstrictive factor. Brit. Heart J., $20,557$. 